\title{
MicroRNAs and cancer drug resistance: over two thousand characters in search of a role
}

\author{
Bruno Costa Gomes, José Rueff, António Sebastião Rodrigues
}

Centre for Toxicogenomics and Human Health; Genetics, Oncology and Human Toxicology, NOVA Medical School, Universidade Nova de Lisboa, Lisboa 1150-008, Portugal.

Correspondence to: Prof. António Sebastião Rodrigues, Centre for Toxicogenomics and Human Health; Genetics, Oncology and Human Toxicology, NOVA Medical School, Universidade Nova de Lisboa, Lisboa 1150-008, Portugal.

E-mail: sebastiao.rodrigues@nms.unl.pt

\begin{abstract}
How to cite this article: Gomes BC, Rueff J, Rodrigues AS. MicroRNAs and cancer drug resistance: over two thousand characters in search of a role. Cancer Drug Resist2019;2:618-33. http://dx.doi.org/10.20517/cdr.2019.55
\end{abstract}

Received: 4 Jul 2019 First Decision: 13 Aug 2019 Revised: 4 Sep 2019 Accepted: 10 Sep 2019 Published: 19 Sep 2019

Science Editor: Frits Peters Copy Editor: Jia-Jia Meng Production Editor: Jing Yu

\begin{abstract}
MicroRNAs (miRNAs), a group of small regulatory noncoding RNAs, transformed our thinking on gene regulation. More than two thousand human miRNAs have been identified thus far. These bind imperfectly to the 3 '-untranslated region of target mRNA and have been involved in several pathological conditions including cancer. In fact, major hallmarks of cancer, such as the cell cycle, cell proliferation, survival and invasion are modulated by miRNAs. Cancer drug resistance (CDR) has also been described as being modulated by miRNAs. CDR remains a burden for cancer therapy and patients' outcome, often resulting in more aggressive tumours that tend to metastasize to distant organs. In this review we discuss the role of miRNAs influencing drug metabolism and drug influx/efflux, two important mechanisms of CDR.
\end{abstract}

Keywords: MicroRNAs, gene regulation, cancer drug resistance, drug transporters, drug metabolism

\section{INTRODUCTION}

Cancer drug resistance (CDR) is a burden in cancer therapy. It has social and economic consequences, and in most cases, it ends in patient death due to treatment failure. Roughly $90 \%$ of patients with metastatic cancers are confronted with treatment failure due to CDR. Drug resistance can be broadly classified into two types, intrinsic and acquired. Intrinsic drug resistance can be defined as a pre-existing genetic condition to a therapy approach that leads tumour cells to survive treatment, therefore contributing to

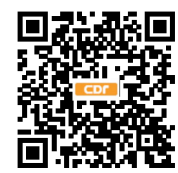


therapy ineffectiveness from the beginning. This can be linked with drug breakdown, alteration of the drug target, resulting in a reduction of efficiency of targeted therapy, and altered drug transport. Acquired drug resistance is developed during therapy and usually due to adaptive processes, such as compensatory signalling pathways (reduced cell death and DNA damage response), drug inactivation, overexpression of drug targets, structural changes in drug targets, increased expression of drug efflux pumps and epigenetics ${ }^{[1]}$. Whatever the mechanisms of drug resistance, it results in treatment failure and consequent proliferation of resistant tumour cells that may metastasize and end up in patient death.

Combined actions of drug-metabolizing enzymes (DMEs) comprise Phase I and Phase II reactions of drug metabolism $^{[2,3]}$. The former increases the polarity of drugs, followed by the conjugation reactions of Phase II that increase their polarity but block the reactivity of polar groups introduced in the earlier reaction. Subsequently, the resulting metabolite is effluxed through the membrane by ATP-binding cassette (ABC) transporters (Phase III reactions) ${ }^{[4]}$. Cancer cells tend to overexpress DMEs and transporters thus evading cancer treatment and becoming resistant to several drugs.

The term microRNAs (miRNAs) was first defined in 2001 by Lee and Ambros ${ }^{[5]}$. However, they were first described in 1993 when two independent groups ${ }^{[6,7]}$ published experiments on the Caenorhabditis elegans lin-4 gene which codes for a pair of small RNAs with antisense complementarity to multiple sites on the 3'-untranslated region (UTR) of the lin-14 gene. Subsequently, they were shown to act on several key cellular processes, such as cell differentiation, cell cycle progression, and apoptosis. Thus, miRNAs can be defined as short (approximately 22 nucleotides) non-coding RNAs that regulate gene expression by binding to the 3'-UTR of messenger RNA. The small size of miRNAs and the pairing between a miRNA and a target site that does not need to be perfect results in a wide selection of genes that can be subject to regulation. Indeed, one miRNA can regulate the expression of multiple mRNAs with wide effects in the transcriptome ${ }^{[8]}$, besides possible regulatory effects on other miRNAs, forming a circuitry of epigenomic regulation. However, the property that makes miRNAs versatile also hampers the prediction of putative targets and the conclusive mechanisms of regulation in the cell. Thus, the study of miRNAs can be very complex. Due to their characteristics and their broad influence in cell homeostasis, soon after their discovery, miRNAs were associated with cancer ${ }^{[9]}$ and referred to as possible regulators of drug resistance $^{[10]}$. More than two thousand human miRNAs have been identified thus far. To date, several studies have shown that drug resistance is influenced by miRNAs. This review intends to summarize the miRNAs that have been shown to regulate drug uptake proteins and Phase I, II and III drug metabolism in different tumours and the corresponding drugs for which the tumours are resistant.

\section{DRUG UPTAKE PROTEINS AND MIRNAS}

Several cancer drugs are absorbed by intestinal epithelial cells which express a variety of influx transporters that are specific for drugs, amino acids, peptides, organic anions and cations, and other nutrients. These transporters are differentially expressed in different regions in the intestine. Peptide transporter 1 (PEPT1/ SLC15A1), organic cation/carnitine transporter 2 (SLC22A5), organic anion transporting polypeptide 2B1 (SLCO2B1), and monocarboxylate transporter 1 (MCT1/SLC16A1) are expressed at the brush-border membrane, whereas organic cation transporter 1 (SLC22A1) is mainly expressed at the basolateral membrane in the small intestine ${ }^{[1]}$. Recent studies have indicated that miRNAs contribute to the differentiation and viability of the intestinal epithelium, and the regional differences in the expression of these transporters in the intestine are dependent on the differentiation of intestinal epithelial cells ${ }^{[12]}$. Thus, abnormal expression of miRNAs can have a clear impact on absorption of several drugs. We summarize in Table 1 the miRNAs that regulate uptake proteins in cell membranes. Figure 1 shows a schematic representation of the regulation of influx and efflux proteins by miRNAS. 
Table 1. Drug uptake proteins and miRNAs that regulate their expression

\begin{tabular}{|c|c|c|c|c|}
\hline Target & miRNA & Model & Drug & Reference \\
\hline SLC15A1 & miR-92b & Caco2-BBE cells & NS & Dalmasso et al. ${ }^{[13]}, 2011$ \\
\hline \multirow{3}{*}{ SLC16A1 } & miR-29b & mhAT3F, MIN6, and HEK293 cells & & Pullen et al. ${ }^{[14]}, 2011$ \\
\hline & miR-29a & & & Pullen et al. ${ }^{[14]}, 2011$ \\
\hline & miR-124 & & & Pullen et al. ${ }^{[14]}, 2011$ \\
\hline SLC34A2 & miR-939 & gastric cancer cell lines and tissue & 5-fluorouacil & Zhang et al. ${ }^{[15]}, 2017$ \\
\hline SLC35F5 & miR-369-3p & NSCLC cells, $16 \mathrm{HBE}$, and HEK293T & cisplatin & Hao et al. ${ }^{[16]}, 2017$ \\
\hline GLUT1 & $\mathrm{miR}-128$ & bladder cancer cells (T24 and EJ) & cisplatin & Li et al. ${ }^{[17]}, 2017$ \\
\hline
\end{tabular}

NS: not stated

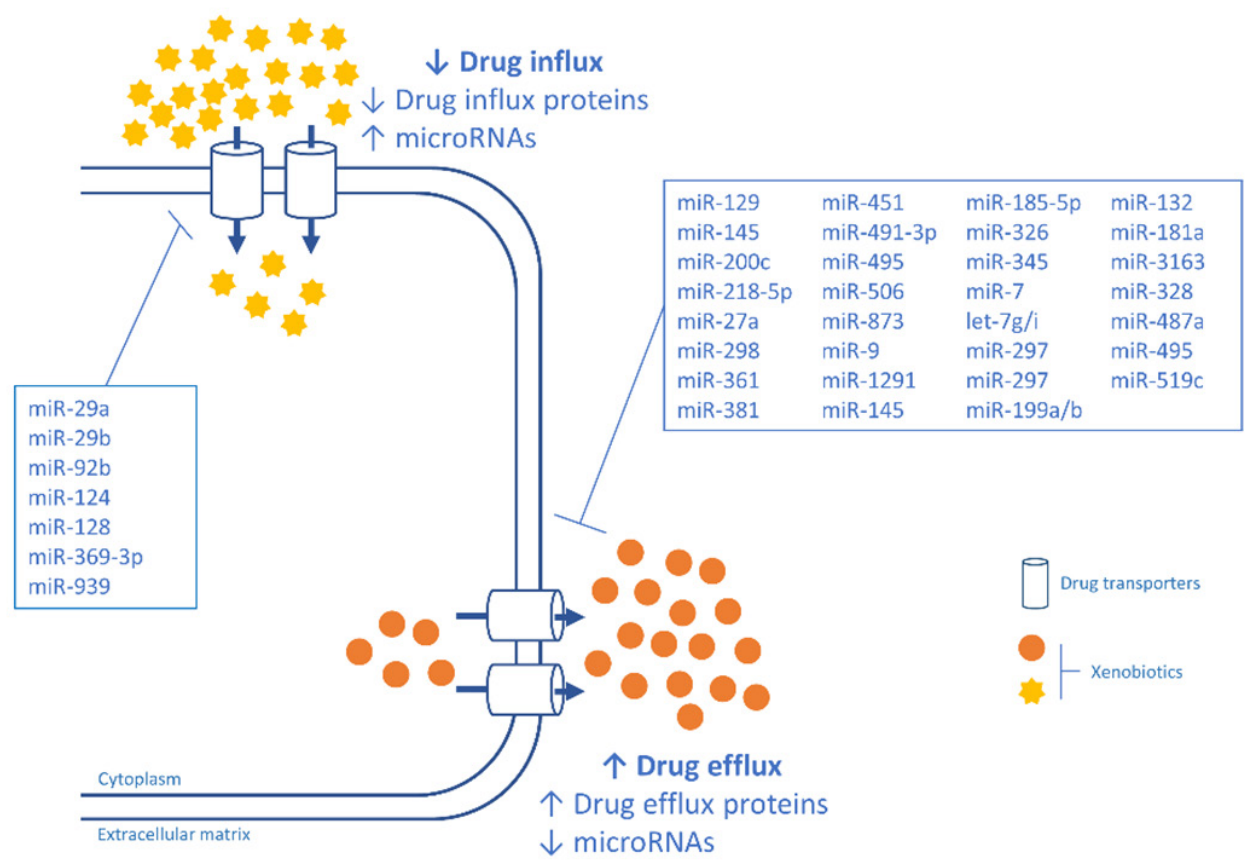

Figure 1. A schematic representation of the regulation of influx and efflux proteins by miRNAS

\section{SLC15A1, SLC16A1 and SLC34A2}

SLC15A1 was shown to be regulated by miR-92b, causing a decrease in the expression of the uptake transporter ${ }^{[13]}$. Pullen et al. ${ }^{[14]}$ showed that miR-29a, miR-29b, and miR-124 regulate SLC16A1, without being its main regulator. The authors refer that these miRs might be a complement mechanism in SLC16A1 expression. Unfortunately, both authors failed to associate these mechanisms with specific drugs and consequent drug resistance. SLC34A2 was shown to be regulated by miR-939 in gastric cancer cell lines and tissues and miR-939 was associated with CDR in gastric cancer patients ${ }^{[15]}$. miR-939 inhibited gastric cancer metastasis and enhanced the sensitivity of gastric cancer cells to 5 -fluorouracil treatment, although uptake of 5-fluorouracil is known to be predominantly by diffusion. Nevertheless, by using multivariate analysis, the authors could show that the combination of both miR-939 and SLC34A2 are indicators of poor prognosis and tumour recurrence in gastric cancer patients, pointing that miR-939 inhibits the SLC34A2/ Raf/MEK/ERK pathway, which is activated in gastric cancer.

\section{SLC35F5}

Hao et al. ${ }^{[16]}$ showed that miR-369-3p may regulate cisplatin chemoresistance by directly targeting the 3 '-UTR of SLC35F5. miR-369-3p acts as an oncogenic miRNA since it is highly expressed in non-small cell lung cancer cells and consequently negatively regulates SLC35F5. Thus, cisplatin is not internalized by the cell and consequently its therapeutic action fails. 
Table 2. Phase I DMEs and miRNAs that regulate their expression

\begin{tabular}{|c|c|c|c|c|}
\hline Target & miRNA & Model & Drug & Reference \\
\hline \multirow[t]{4}{*}{ CYP1A2 } & miR-132-5p & HepaRG cells & Lansoprazole & Chen et al. ${ }^{[26]}, 2017$ \\
\hline & & Huh-7 cells & & \\
\hline & & HepG2 cells & & \\
\hline & & HepG2 cells & Flutamide & \\
\hline \multirow[t]{13}{*}{ CYP1B1 } & miR-187-5p & NSCLC & NS & Mao et al. ${ }^{[35]}, 2016$ \\
\hline & & A549 & & \\
\hline & & SPC-A-1 & & \\
\hline & miR-27b & HeLa cells & NS & Tsuchiya et al. ${ }^{[31]}, 2006$ \\
\hline & & MCF-7 cells & & \\
\hline & & Jurkat cells & & \\
\hline & & HepG2 cells & Fumonisin $B_{1}$ & Chuturgoon et al. ${ }^{[33]}, 2014$ \\
\hline & miR-200c & Caki-1 cells & Docetaxel & Chang et al. ${ }^{[34]}, 2015$ \\
\hline & & Caki-2 cells & & \\
\hline & & A498 cells & & \\
\hline & & ACHN cells & & \\
\hline & & $786-\mathrm{O}$ cells & & \\
\hline & & 769-P cells & & \\
\hline \multirow[t]{6}{*}{ CYP2E1 } & miR-552 & $\mathrm{PLC} / \mathrm{PRF} / 5$ cells & NS & Miao et al. ${ }^{[40]}, 2016$ \\
\hline & & HepG2 cells & & \\
\hline & & C57/BL6 mice & & \\
\hline & miR-378 & HEK293 & & Mohri et al. ${ }^{[38]}, 2010$ \\
\hline & miR-132 & Primary Rat & Rapamycin & Shukla et al. ${ }^{[39]}, 2013$ \\
\hline & miR-212 & Hepatocytes & & \\
\hline \multirow[t]{3}{*}{ CYP3A4 } & miR-27b & Human liver tissue & Atorvastatin & Liu et $a l .{ }^{[43]}, 2016$ \\
\hline & miR-206 & & & \\
\hline & miR-27b & [C1 cells LS- 180 cells & Cyclophosphamide & Pan et al. ${ }^{[42]}, 2009$ \\
\hline
\end{tabular}

NS: not stated; DMEs: drug metabolizing enzymes

\section{GLUT1}

Regarding GLUT1 our search only retrieved one study where miR-128 regulates GLUT1 ${ }^{[17]}$. The authors showed that the overexpression of miR-128 lowered the rate of glucose uptake and the total level of GSH. It also enhanced the sensitivity of bladder cancer to cisplatin.

\section{PHASE I PROTEINS AND miRNAs}

Various studies have been performed on transcriptional and translational regulation of the DMEs ${ }^{[18-20]}$. However, these studies have not elucidated the mechanisms of their post-transcriptional regulation. MiRNAs are regulators of DMEs, however, few studies have shown a direct involvement of this regulation in $\mathrm{CDR}^{[21]}$.

One of the key players of drug metabolism are cytochrome P450 (CYP) enzymes that catalyse oxidation reactions of xenobiotics ${ }^{[22]}$. More than $90 \%$ of the reactions involved in the metabolism of all endobiotics and xenobiotics are catalysed by $\mathrm{P} 450 \mathrm{~s}^{[23]}$. The majority of CYP reactions are catalysed by a set of four CYP families: $1 \mathrm{~A}, 2 \mathrm{C}, 2 \mathrm{D}$, and $3 \mathrm{~A}$, with the largest fraction of the CYP reactions being catalysed by CYP3A enzymes. One of the most important CYPs is CYP3A4, which metabolizes from $13 \%$ of general chemicals to $27 \%$ of drugs ${ }^{[23]}$. Consequently, regulation of DMEs is crucial to drug efficacy and is associated with drug failure and/or drug resistance. In Table 2 we show the known miRNAs that regulate CYPs and influence CDR.

\section{CYP1A2}

CYP1A2 is an important DME since it represents $13 \%$ of all CYPs expressed in the liver and metabolizes about $5 \%$ of currently used drugs. CYP1A2 is also important in the metabolism of endobiotics like steroids 
and environmental pollutants like polycyclic aromatic hydrocarbons. Several genetic polymorphisms have been associated with increased activity and linked with lung cancer ${ }^{[24,25]}$. Regarding post-translational regulation of CYP1A2, one study reported that miR-132-5p decreases CYP1A2 gene expression and influences hepatic cells in the metabolisation of lansoprazole and flutamide ${ }^{[26]}$. The authors showed direct targeting of miR-132-5p to CYP1A2 and also demonstrated that the decreased expression of CYP1A2 attenuates lansoprazole- and flutamide mediated toxicity.

\section{CYP1B1}

$\mathrm{CYP} 1 \mathrm{~B} 1$ is highly expressed in oestrogen target tissues and catalyses the metabolic activation of several procarcinogens (e.g., heterocyclic amines, polycyclic hydrocarbons) and the 4-hydroxylation of $17 \beta$-oestradiol ${ }^{[27,28]}$. It is also abundant in tumour tissues. It was already shown that polymorphisms in CYP1B1 can influence its activity and thus are associated with cancer, namely breast cancer ${ }^{[29]}$. CYP1B1 gene expression can also be modulated by aryl hydrocarbon receptor, an important mediator of toxic response and consequently drug efficacy ${ }^{[30]}$. In what concerns post-transcriptional regulation, a few authors have shown that miRNAs can influence CYP1B1 gene expression. One of the first authors showing this association was the group of Tsuchiya et al. ${ }^{[31]}$ who validated miR-27b as a regulator of CYP1B1 in cervical and breast cancer cell lines, and also reported an inverse association of miR-27b expression and CYP1B1 protein expression in breast tissue samples. These authors showed through immunohistochemistry that miR-27b decreased gene expression together with strong CYP1B1 tissue staining. However, the authors did not show an association of this pattern with common breast CDR. Nevertheless, since biotransformation of tamoxifen, a widely used drug in breast cancer treatment, occurs via $\mathrm{CYP}_{1} \mathrm{~B}_{1}{ }^{[32]}$, the mis-expression of CYP1B1 in breast cancer cells due to miR-27b could influence the efficacy of tamoxifen. Interestingly, Chuturgoon et al ${ }^{[33]}$ also reported the involvement of miR-27b in the metabolisation of fumonisin B1, a known mycotoxin, through direct targeting of $\mathrm{CYP} 1 \mathrm{~B} 1$ and hepatic neoplastic transformation, reinforcing the idea that miRNAs and CYPs interact in the metabolisation of drugs and environmental and food contaminants. Recently, miR-200c was also predicted to be involved in CYP1B1 regulation in renal cell cancer and resistance to docetaxel ${ }^{[34]}$. The authors used several renal cancer cell lines to show this association and proved that miR-200c directly targets CYP1B1 and the low expression of miR-200c in these cell lines is correlated with an increased expression of CYP1B1. More recently, Mao et al ${ }^{[35]}$ showed that miR-187-5p is decreased in non-small lung cancer and regulates CYP1B1, a direct target of miR-187-5p. The authors used lung cancer cell lines to demonstrate the negative correlation of both miR-187-5p and CYP1B1 and show its direct targeting. They also showed a correlation between the low expression of miR-187-5p with TNM stage and postoperative survival, and high expression of miR-187-5p with growth and metastasis. However, the authors failed to associate these results with drug resistance.

\section{CYP2E1}

CYP2E1 represents approximately 7\% of total CYPs in the human liver. CYP2E1 catalyses the metabolism of several low molecular weight xenobiotics, such as organic solvents (e.g., ethanol, acetone, and chloroform), and several procarcinogens (e.g., N-nitrosodimethylamine and N-nitrosomethylethylamine). Interestingly, CYP2E1-induced ROS generation influences migration in breast cancer cells, thus may be involved in breast cancer metastasis ${ }^{[36]}$. Genetic polymorphisms have been associated with CYP2E1 efficiency and influence lipid metabolism and nicotine clearance in the blood ${ }^{[37]}$. Regarding epigenetic regulation, miR-378 was confirmed as a CYP2E1 regulator in kidney cell lines by Mohri et al. ${ }^{[38]}$. The authors showed that the overexpression of miR-378 significantly decreased CYP2E1 protein levels and enzyme activity. An interesting detail is that miR-378 did not enable the degradation of the CYP2E1 mRNA. Additionally, an inverse association of the expression levels of miR-378, CYP2E1 mRNA and protein as well as enzyme activity were revealed using a panel of 25 human livers. Unfortunately, the authors did not show any association with cancer drug failure. However, other authors showed an 
Table 3. DMEs of Phase II and miRNAs that regulate their expression

\begin{tabular}{|c|c|c|c|c|}
\hline Target & miRNA & Model & Drug & $\begin{array}{l}\text { Reference } \\
\end{array}$ \\
\hline UGT1A1 & $\begin{array}{l}\text { miR-21-3p } \\
\text { miR-141-3p } \\
\text { miR-200a-3p }\end{array}$ & NS & NS & Papageorgiou et al. ${ }^{[53]}, 2017$ \\
\hline UGT2B4 & $\begin{array}{l}\text { miR-216b-5p } \\
\text { miR-135a } \\
\text { miR-410 }\end{array}$ & $\begin{array}{l}\mathrm{HepG2} \\
\text { NS }\end{array}$ & $\begin{array}{l}\text { Epirubicin } \\
\text { NS }\end{array}$ & $\begin{array}{l}\text { Dluzen et } a l_{.}^{[51]}, 2016 \\
\text { Wijayakumara et al. } .^{[54]}, 2017\end{array}$ \\
\hline UGT2B7 & miR-3664 & & & \\
\hline UGT2B10 & $\operatorname{miR} 216 b-5 p$ & Liver cancer & Epirubicin & Dluzen et al. $.^{[51]}, 2016$ \\
\hline UGT2B17 & miR-376c & NS & NS & Margaillan et al. ${ }^{[52]}, 2016$ \\
\hline GSTP1 & miR-133a & Head and neck, oesophageal, bladder & Cisplatin and carboplatin & Moriya et al. ${ }^{[50]}, 2012$ \\
\hline SULT1A1 & miR-631 & Breast cancer & Actinomycin D & Yu et al. ${ }^{[47]}, 2010$ \\
\hline
\end{tabular}

NS: not stated; DMEs: drug metabolizing enzymes

association of an increased expression of CYP2E1, low expression of miR-132 and miR-212 with rapamycin resistance in cultured rat hepatocytes ${ }^{[39]}$. More recently, miR-552 was shown to regulate CYP2E $1^{[40]}$. This study had the meticulousness of showing that miR-552 can influence CYP2E1 expression in a transcriptional and post-transcriptional manner. In fact, the authors showed that a non-seed region regulation by miR-552 can occur, thus influencing transcription and translation independently. However, the authors did not show any association with cancer drugs.

\section{CYP3A4}

CYP3A4 represents $30 \%$ of the CYP expression in the liver and metabolizes approximately $27 \%$ of all commercial drugs. For that reason, it is one of the most studied CYPs. As with the other CYPs, it has several isoforms that results from genetic polymorphisms ${ }^{[41]}$. Some authors showed that CYP3A4 can be regulated post-transcriptionally by miR-27b ${ }^{[42]}$. These authors also showed that an overexpression of miR-27b in the PANC1 cell line led to a lower sensitivity to cyclophosphamide, showing the impact on drug response and resistance. Other authors also showed that miR-27b can influence the metabolism of atorvastatin in the liver, a known statin used to low cholesterol levels in the blood ${ }^{[43]}$. Moreover, these authors also showed in the same study that miR-206 can regulate CYP3A4 and influence atorvastatin metabolism. This study was important to understand the mechanism of atorvastatin resistance, since it can affect $60 \%$ of the patients. Although statin is not a common cancer drug, a recent study performed in ovarian cancer ${ }^{[4]]}$ showed that atorvastatin has a role in proliferation and metastasis. In fact, the authors showed that atorvastatin inhibited cell proliferation of ovarian cancer cells in a dose-dependent manner and that its anti-proliferative activity was linked with induction of apoptosis, autophagy, cellular stress and cell cycle arrest via AKT/mTOR and MAPK pathways. Also, atorvastatin changed cell adhesion and invasion and decreased expression of VEGF and MMP9, known important proteins in epithelial-tomesenchymal transition ${ }^{[44]}$.

\section{PHASE II ENZYMES AND miRNAs}

Regarding Phase II DMEs, although these enzymes are important players in cancer drug detoxification, few studies have linked them with miRNAs regulation and CDR. A summary of the miRNAs that regulate Phase II enzymes can be seen in Table 3. Figure 2 shows a schematic representation of the regulation of DMEs by miRNAS.

\section{SULT1A1}

SULT1A1 is a member of the sulfotransferase (SULT) family, which catalyse the transfer of the sulfonyl group from 3'-phosphoadenosine 5'-phosphosulfate (PAPS) to nucleophilic groups of a variety of xenobiotic 

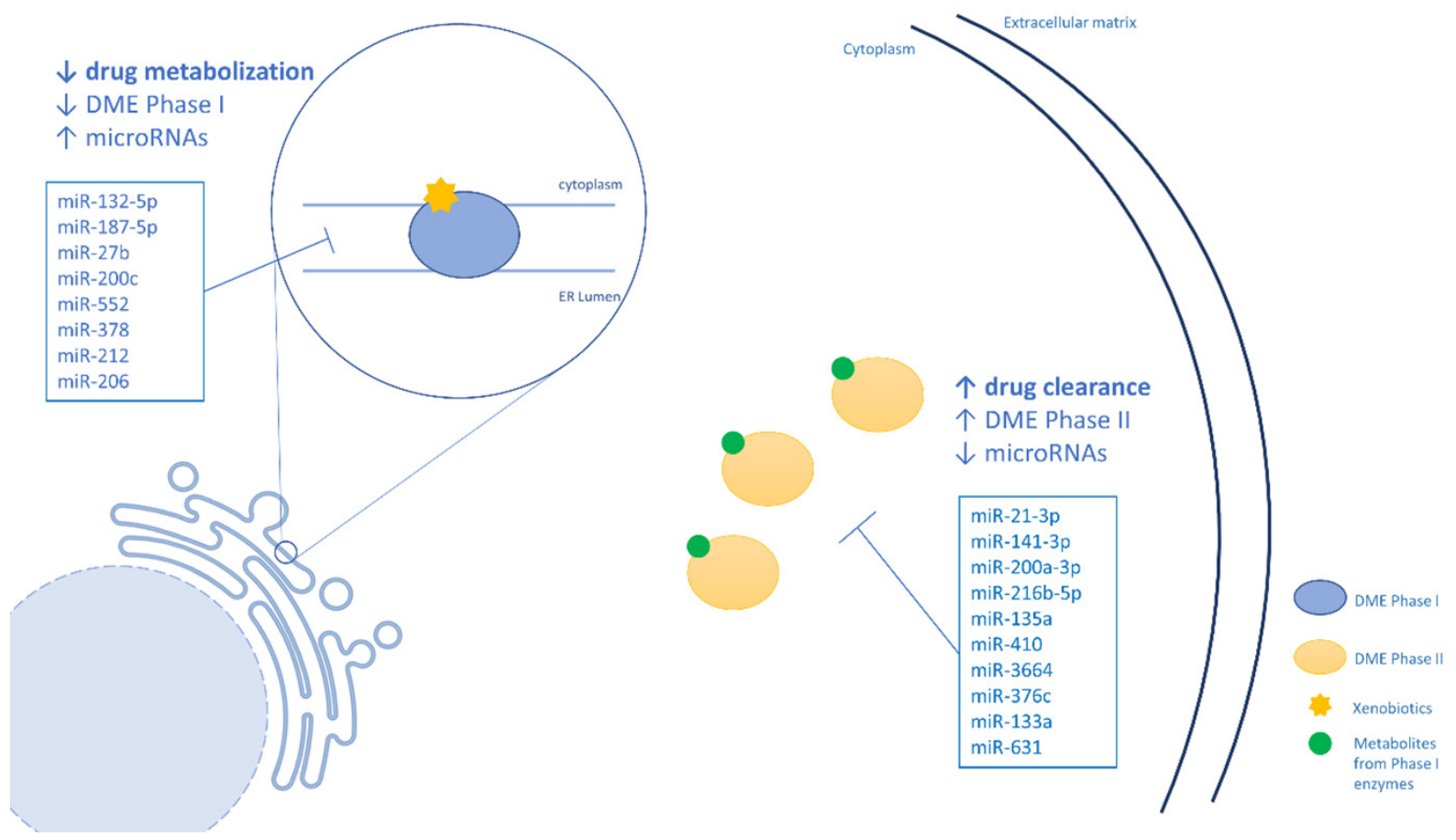

Figure 2. A schematic representation of the regulation of DMEs by by miRNAS. DMEs: drug metabolizing enzymes

and endogenous compounds, thus increasing their solubility and excretion ${ }^{[45]}$. SULT1A1 is the most highly expressed SULT in the liver, and several therapeutic agents, such as 4-hydroxytamoxifen, are substrates of SULT1A1. Variability in the activity levels of SULT1A1 can influence the efficacy of some drugs and consequently induce drug resistance ${ }^{[46]}$. Interestingly, genetic polymorphisms in SULT1A1, such as copy number variation and single nucleotide polymorphisms (SNPs), are associated with altered enzymatic activity. In fact, some authors ${ }^{[47]}$ studied SNPs in the $3^{\prime}$-UTR region of SULT1A1 and in silico analyses predicted that the $973 \mathrm{C} \rightarrow \mathrm{T}$ SNP could influence the binding of miR-631. Taking this into account, in vitro luciferase reporter assays and overexpression of miRNAs inhibitors in ZR75-1, MCF7, and MCF10A breast cell lines confirmed that SULT1A1 is a direct target of miR-631 ${ }^{[47]}$.

\section{GSTP1}

GSTP1 is a member of the GST enzyme superfamily, that catalyses the conjugation of electrophiles with glutathione in Phase II reactions, including platinum drugs such as cisplatin and carboplatin ${ }^{[48]}$. GSTP1 plays several roles in cells, such as in stress responses, signalling, and apoptosis. GSTP1 knockdown selectively influenced cisplatin and carboplatin chemosensitivity, cell invasion and migration ${ }^{[49]}$. Overexpression of GSTP1 has been observed in many types of cancer and cell lines either inherently or made resistant to chemotherapy drugs, including cisplatin and various alkylating agents. As other DMEs, GSTP1 can be regulated by miRNAs and Moriya et al. ${ }^{[50]}$ showed that reduced expression of miR-133a leads to an increased expression of GSTP1, contributing to drug resistance. The authors showed that the transfection of miR-133a repressed GSTP1 expression at both mRNA and protein levels in several different cell lines. Thus, the functional significance of miR-133a was investigated using head and neck squamous cell carcinoma (SCC), oesophageal SCC, and bladder cell lines. These authors could show that restoration of miR-133a expression inhibited cancer cell proliferation, invasion, and migration, suggesting that miR-133a may function as a tumour suppressor.

More recently, some studies were published showing the importance of miRNAs in the regulation of UDPglucuronosyltransferases (UGTs) enzymes ${ }^{[51-54]}$. The UGTs are critical for the efficient elimination of several 
Table 4. Drug transporters and miRNAs that regulate their expression

\begin{tabular}{|c|c|c|c|c|}
\hline Target & miRNA & Model & Drug & Reference \\
\hline \multirow[t]{17}{*}{ ABCB1 } & miR-129 & ovarian & paclitaxel & Wang et al. ${ }^{[68]}, 2018$ \\
\hline & & gastric cancer & cisplatin & Lu et al. ${ }^{[69]}, 2017$ \\
\hline & miR-145 & colon carcinoma, kidney & NS & Ikemura et al. ${ }^{[73]}, 2013$ \\
\hline & miR-200c & Breast Cancer & doxorubicin & Chen et al. ${ }^{[76]}, 2012$ \\
\hline & $\operatorname{miR}-218-5 p$ & gallbladder & gemcitabine & Wang et al. ${ }^{[74]}, 2017$ \\
\hline & $\operatorname{miR}-27 a$ & Ovarian cancer & doxorubicin & Zhu et al. ${ }^{[79]}, 2008$ \\
\hline & miR-298 & Breast Cancer & doxorubicin & Bao et al. ${ }^{[77]}, 2012$ \\
\hline & miR-361 & gastric cancer & oxaliplatin & Wu et al. ${ }^{[70]}, 2018$ \\
\hline & miR-381 & Breast Cancer & cisplatin & Yi et al. ${ }^{[80]}, 2019$ \\
\hline & & K562 cell line & adriamycin & Xu et al. ${ }^{[81]}, 2013$ \\
\hline & miR-451 & Breast Cancer & doxorubicin & Kovalchuk et al. ${ }^{[78]}, 2008$ \\
\hline & miR-491-3p & hepatocellular carcinoma & doxorubicin \& vinblastin & Zhao et al. ${ }^{[71]}, 2017$ \\
\hline & $\operatorname{miR}-495$ & ovarian cancer $\&$ gastric cancer & doxorubicin \& taxol & Zou et al. ${ }^{[83]}, 2017$ \\
\hline & & K562 cell line & adriamycin & Xu et al. ${ }^{[81]}, 2013$ \\
\hline & miR-506 & colorectal cancer & oxaliplatin & Zhou et al. ${ }^{[72]}, 2017$ \\
\hline & miR-873 & ovarian cancer & cisplatin \& paclitaxel & Wu et al. ${ }^{[75]}, 2016$ \\
\hline & $\operatorname{miR}-9$ & chronic myelogenous leukemia & adriamycin & Li et al. ${ }^{[82]}, 2017$ \\
\hline \multirow[t]{7}{*}{$\mathrm{ABCC} 1$} & miR-1291 & pancreatic cancer, lung cancer, kidney & doxorubicin & Pan et al. ${ }^{[88]}, 2013$ \\
\hline & miR-145 & gallbladder & cisplatin & Zhan et al. ${ }^{[89]}, 2016$ \\
\hline & & Breast Cancer & doxorubicin & Gao et al.. ${ }^{[90]}, 2016$ \\
\hline & miR-185-5p & non-small cell lung cancer & cisplatin & Pei et al. ${ }^{[91]}, 2016$ \\
\hline & $\operatorname{miR}-326$ & MCF-7 cells & VP-16 and doxorubicin & Liang et al. ${ }^{[87]}, 2010$ \\
\hline & miR-345 & MCF-7 cells & cisplatin & Pogribny et al. ${ }^{[86]}, 2010$ \\
\hline & miR-7 & MCF-7 cells & cisplatin & Pogribny et al. ${ }^{[86]}, 2010$ \\
\hline $\mathrm{ABCC} 10$ & let-7g/i & esophageal carcinoma & cisplatin & Wu et al. ${ }^{[75]}, 2016$ \\
\hline $\mathrm{ABCC} 2$ & miR-297 & HCT116 cells & oxaplatin and vincristine & Xu et al. ${ }^{[92]}, 2012$ \\
\hline \multirow[t]{9}{*}{ ABCG2 } & mi-199a/b & colorectal cancer & cisplatin & Chen et al. ${ }^{[102]}, 2017$ \\
\hline & miR-132 & gastric cancer & cisplatin & Zhang et al. ${ }^{[103]}, 2017$ \\
\hline & miR-181a & Breast Cancer & $\mathrm{MX}$ & Jiao et al. ${ }^{[98]}, 2013$ \\
\hline & miR-3163 & Retinoblastoma Cancer & $\begin{array}{l}\text { cisplatin, carboplatin, vincristine, } \\
\text { doxorubicin, and etoposide }\end{array}$ & Jia et $a l_{.[104]}, 2016$ \\
\hline & miR-328 & Breast Cancer & $\mathrm{MX}$ & Li et al. ${ }^{[99]}, 2011$ \\
\hline & & kidney, breast cancer & $M X$ & Pan et al. ${ }^{[100]}, 2009$ \\
\hline & $\operatorname{miR}-487 a$ & MCF-7 cells & $M X$ & Ma et al. ${ }^{[101]}, 2013$ \\
\hline & miR-495 & non-small cell lung cancer & cisplatin & Guo et al. ${ }^{[105]}, 2018$ \\
\hline & miR-519c & kidney, breast cancer & $\mathrm{MX}$ & Li et al. ${ }^{[99]}, 2011$ \\
\hline
\end{tabular}

NS: not stated; MX: mitoxantrone

drugs, including cancer drugs.

\section{UGT1A}

The UGT1A subfamily is involved in the metabolism of more than half of the drugs eliminated by glucuronidation. Among other examples, we can refer irinotecan, raltegravir and muycophenolic acid, drugs involved in cancer therapy, HIV and organ rejection, respectively. Recently, some authors showed that UGT1A1 can be regulated by miR-21-3p, miR-141-3p and miR-200a-3 ${ }^{[53]}$. Although the authors did not show any association with drug resistance, they demonstrated that polymorphisms on the 3'-UTR region of UGT1A1 can influence the targeting of these miRNAs and consequently its activity, namely, rs10929303, rs1042640, and rs8330 polymorphisms.

\section{UGT2B}

The UGT2B subfamily is responsible for metabolic clearance of several endobiotics, such as bile acids and steroid hormones, and xenobiotics, such as cancer drugs ${ }^{[55]}$. In fact, Dluzen et al. ${ }^{[51]}$ showed that miR-216b-5p 
can influence epirubicin treatment efficacy by targeting UGT2B4 and UGTB10 in liver cancer. Interestingly, the approach of these authors was similar to the previous one that studied UGT1A1, studying the 3'-UTR region of UGT2B isoforms and associating these variants with miRNAs hybridization to messenger RNA. Other authors also showed that UGT2B4 can be regulated by miR-216b-5p and miR-135a ${ }^{[54]}$, although not necessarily associated with CDR. Another isoform of UGT2B, UGT2B7, was shown to be regulated by miR-366 ${ }^{[54]}$. Finally, miR-376c was showed to regulate UGT2B17 ${ }^{[52]}$. Once more, the authors failed to show an association with drug resistance but showed a possible association with steroid metabolism and prostate cancer.

\section{PHASE III PROTEINS AND miRNAs}

Phase III proteins are known to be responsible for drug transport through cell membranes. It is a critical step in allowing access of some compounds to intracellular targets. For this reason, the involvement of drug transport is one of the most studied mechanisms in $\mathrm{CDR}^{[56]}$. Multidrug resistance (MDR) is frequently linked to overexpression of one or more of drug transporters. One of these phase III proteins are the $A B C$ transporters, which have an important cellular role in the efflux of several endobiotics and xenobiotics $^{[57]}$. Approximately 50 different $A B C$ transporters have been identified and classified in seven families from ABCA through $A B C G^{[58]}$. The relevance of miRNAs in the regulation of $A B C$ transporters has been reviewed before ${ }^{[11,59,60]}$, and probably are the most studied drug metabolism proteins in what concerns miRNAs regulation. In Table 4 we summarize all miRNAs described as being involved in drug resistance by regulation $\mathrm{ABC}$ transporters.

\section{АВCB1}

$\mathrm{ABCB} 1$ is probably the most studied $\mathrm{ABC}$ transporter. It is also known as MDR1 or P-gp transporter and is often overexpressed in tumour cells with chemotherapeutic resistance, as well as in resistant cancer cell lines ${ }^{[61]}$. An overexpression or altered function due to genetic polymorphisms of ABCB1 increases resistance to taxanes (e.g., paclitaxel and docetaxel) ${ }^{[62]}$, epipodophyllotoxin derivatives (e.g., etoposide and teniposide) ${ }^{[63]}$, anthracyclines (e.g., doxorubicin) ${ }^{[63,64]}$, antibiotics (e.g., actinomycin D) ${ }^{[63,65]}$, vinca alkaloids (e.g., vinblastine and vinorelbine) ${ }^{[66]}$, and tyrosine kinase inhibitors (e.g., imatinib and dasatinib) ${ }^{[67]}$.

To date, several studies have been published reporting a correlation between miRNAs expression and $\mathrm{ABCB} 1$. Wang et al ${ }^{[68]}$ showed that $\mathrm{ABCB} 1$ was a direct target of miR-129 and that urothelial carcinoma associated 1 (UCA1) de-repressed $A B C B 1$ expression by sponging miR-129. Thus, the authors revealed an interesting regulatory axis UCA1/miR-129/ABCB1 that sensitizes ovarian cancer cells to paclitaxel. In another study, it was shown that miR-129 also sensitizes cancer cells to cisplatin, namely in gastric cancer, by regulating $\mathrm{ABCB} 1^{[69]}$. The confirmation of direct targeting was done in BGC823/DDP and MKN45/DDP cell lines resistant to cisplatin that presented low expression of miR-129. The authors also confirmed that miR-129 expression was significantly downregulated and ABCB1 upregulated in gastric cancer tissues of cisplatin-resistant patients. Other authors also reported this sponging activity by another long non-coding RNA, BLACAT1, which regulates miR-361 expression and consequently increases ABCB1 expression. This regulatory axis BLACAT1/miR-361/ABCB1 can influence resistance to oxaliplatin ${ }^{[70]}$. Albeit indirectly, miR-491-3p was shown to regulate $\mathrm{Sp3}$, a transcription factor of $\mathrm{ABCB} 1$, in hepatocellular carcinoma and consequently doxorubicin and vinblastine resistance. The authors observed this regulatory axis miR-491-3p/ $\mathrm{Sp} 3 / \mathrm{ABCB} 1$ in cell lines and tissue from cancer patients ${ }^{[7]}$. Similarly, miR-506 seems to enter a regulatory axis with the Wnt/ $\beta$-catenin pathway which regulates $\mathrm{ABCB} 1$. This was demonstrated in colorectal cancer cell lines and helped clarify the resistance mechanism of oxaliplatin ${ }^{[72]}$.

Ikemura et al. ${ }^{[73]}$ showed that miR-145 regulates ABCB1 expression in intestinal epithelial cells and kidney cells. The authors did not show any association with chemotherapeutics but instead showed an increased 
efflux activity with rhodamine 123 . In another study ${ }^{[7]}$ miR-218-5p was shown to indirectly regulate $\mathrm{ABCB} 1$ by inhibiting the translation of PRKCE, a member of the protein kinase $\mathrm{C}$ family, which is known as an $\mathrm{ABCB} 1$ activator. The authors used an in vitro and in vivo approach to show these results and in fact, were capable of inducing gemcitabine sensitization in gallbladder cancer in both models. With the same approach, other authors ${ }^{[75]}$ could show that miR-873 can mediate resistance to paclitaxel and cisplatin in ovarian cancer.

In one study with breast cancer, a correlation of miR-200c with poor response to neoadjuvant chemotherapeutics could be shown ${ }^{[76]}$. Unfortunately, the authors did not follow ABCB1 mRNA and protein expression in the patients. Instead, they used a doxorubicin-resistant breast cancer cell line (MCF7/ADR) to prove that miR-200c regulates $A B C B 1$ by directly targeting its 3'-UTR. Curiously, miR-200c expression was observed to be downregulated over 800 -fold in this resistant cell line. In two other studies ${ }^{[77,78]}$ the importance of miRNAs in the resistance of doxorubicin in breast cancer was shown, namely, miR-298 and miR-451. Kovalchuk et al ${ }^{[78]}$ showed that the ABCB1 is highly expressed in the MCF-7-resistant breast tumour cell line when compared with wild type MCF-7, and that a negative correlation exists between ABCB1 and miR-451 expression. Transfection of miR-451 re-established the sensitivity of the MCF-7-resistant cells to doxorubicin. Conversely, a decreased expression of miR-451 is correlated with higher expression of $\mathrm{ABCB} 1$ in other drug resistant cells, more precisely in a human ovarian cancer cell line and a human cervix carcinoma cell line. Here, the expression of miR-27a and miR-451 were upregulated in multidrug resistant cells compared with their parental lines, downregulating expression of the $A B C B 1$ gene ${ }^{[79]}$. These results suggest that the involvement of specific miRNAs in drug resistance should be taken cautiously, since the results could depend on various factors, including the cell lines under study. Bao et al ${ }^{[77]}$ used a different breast tumour cell line, MDA-MB-231, to show that miR-298 regulates $A B C B 1$ gene expression and increases resistance to doxorubicin. Remarkably, the authors also showed that miRNAs processing is altered in the resistant cell lines, since DICER is weakly expressed and higher levels of miR-298 precursor was detected instead of the mature form. Also in breast cancer, miR-381 overcomes cisplatin resistance by targeting $\mathrm{ABCB} 1{ }^{[80]}$. Their results showed that miR-381 was down-regulated in cisplatin resistant breast cancer tissues and cell lines, and $\mathrm{ABCB} 1$ expression is inversely correlated. The authors observed an interaction between miR-381/ABCB1 and showed that inhibition of miR-381 reduced sensitivity of MCF-7 and MDA-MB-231 cells to cisplatin. MDR1 knockdown could overcome cisplatin resistance in MCF-7 and MDA-MB-231 cisplatin resistant cells, while MDR1 overexpression led to DDP resistance in MCF-7 and MDA-MB-231 cells. Thus, a biological interaction between both was demonstrated. miR-381 seems also to regulate adriamycin resistance in chronic myelogenous leukaemia K562 cell lines ${ }^{[81]}$. Functional analysis indicated that restoring expression of miR-381 and also miR-495 in K562 adriamycin-resistant cells was associated with an inverse expression of $\mathrm{ABCB} 1$ and consequently increased drug accumulation in the cells and drug sensitisation. Other authors ${ }^{[82]}$ also showed that miR-9 can have the same effect in adriamycin resistance. Another study ${ }^{[83]}$ showed that miR-495 can sensitize ovarian and gastric cancer cell lines to a mixture of taxol and doxorubicin. The authors started showing that resistant cell lines can tolerate a high dosage of this drug mixture and have increased levels of ABCB1. Later, they showed that miR-495 is inversely correlated with $A B C B 1$ and miR-495 expression induction lowered $A B C B 1$ expression levels and sensitized cells to taxol and doxorubicin. This pattern was also shown in vivo.

\section{$A B C C 1, A B C C 2$ AND ABCC10}

The ABCC transporter family needs the presence of glutathione for its activity and ABCC1 and ABCC2 (also known as MRP1 and MRP2) share 49\% amino acid residues. Altered ABCC1 activity is known to confer resistance to vincristine, etoposide, anthracyclines (doxorubicin, daunorubicin, epirubicin), mitoxantrone (MX), flutamide, and methotrexate ${ }^{[84]} . \mathrm{ABCC} 2$ can mediate resistance to methotrexate, cisplatin, irinotecan, paclitaxel, and vincristine. Both $\mathrm{ABCC} 1$ and $\mathrm{ABCC} 2$ are mainly expressed in solid tumours 
from the kidney, colon, breast, lung, ovary, and as well as in cells from patients with acute myelogenous leukaemia ${ }^{[85]}$. ABCC10 (also known as MRP7) is genetically more distant (33\%-36\%) and is also expressed in several tissues. It can modulate resistance to paclitaxel, docetaxel, vincristine, vinblastine, Ara-C, gemcitabine and epothilone- $\mathrm{B}^{[85]}$.

Regarding ABCC1, various studies were published showing a regulation by miRNAs. Pogribny et al. ${ }^{[86]}$ showed that miR-345 and miR-7 increase sensitivity to cisplatin in breast cancer cells. The authors used a MCF-7 cell line resistant to cisplatin which expresses high levels of ABCC1 and lower levels of miR-345 and miR-7. Also in breast cancer, other authors showed that miR-326 represses ABCC1 expression and sensitizes VP-16 resistant MCF-7 cells to VP-16 and doxorubicin ${ }^{[8]}$. Another study reported that miR-1291 is originated from a nucleolar RNA, SNORA34, and influences doxorubicin resistance in pancreatic cancer, lung cancer, kidney cancer ${ }^{[8]}$. More recently, miR-145 was shown to regulate cisplatin resistance in gallbladder cancer cell lines by targeting ABCC1. Lower miR-145 and higher ABCC1 expression levels in gallbladder tissue predicted poor prognosis of gallbladder cancer patients who received chemotherapy ${ }^{[89]}$. Another microRNA, miR-145, was also reported to modulate doxorubicin resistance by targeting $\mathrm{ABCC} 1$ in an in vitro and in vivo study ${ }^{[90]}$. miR-185-5p was shown to control cisplatin resistance via ABCC1 in non-small cell lung cancer. This inverse association was only demonstrated in lung cancer cell lines A549 resistant to cisplatin, thus, lacking data in lung cancer tissue ${ }^{[91]}$.

Regarding $\mathrm{ABCC} 2$, only one study has been published showing an inverse correlation of miRNA with $\mathrm{ABCC} 2$. Xu et al. ${ }^{[92]}$ reported the validation of ABCC2 as a target of miR-297 and consequently the downregulation of its expression. An inverse correlation was demonstrated in colorectal carcinoma cell lines resistant to oxaliplatin and vincristine. After transfection of miR-297-mimics, in vitro and in vivo, these cancer cells overcame resistance to oxaliplatin.

Regarding ABCC10 also one article has reported its modulation by miRNAs. In this study, miR-let-7g/i was shown to hinder ABCC10 translation in oesophageal carcinoma and thus influencing cisplatin resistance. The authors also refer a regulation of proliferation and apoptosis possibly through interaction with BAG3, a protein involved in several cellular processes. However, this assumption needs confirmation with further studies ${ }^{[93]}$.

\section{ABCG2}

ABCG2 is mainly expressed in the gut, bile canaliculi, placenta, blood-testis and blood-brain barriers. $\mathrm{ABCG} 2$ is responsible for the transport of several cancer therapeutic drugs. In cancer cells, as with other $\mathrm{ABC}$ transporters, $\mathrm{ABCG} 2$ is highly expressed, resulting in reduced drug concentrations inside the cell and consequent drug resistance ${ }^{[94]}$. Increased ABCG2 expression has been linked to resistance to MX, topotecan, 7-ethyl-10-hydroxycamptothecin, anthracycline and tamoxifen in breast cancer ${ }^{[95-97]}$. In a microarray analysis approach Jiao et al. ${ }^{[98]}$ showed that miR-181a is significantly downregulated while ABCG2 is overexpressed in MCF-7 cells resistant to MX. Using the same cells, the authors transfected them with miR-181a which abrogated ABCG2 expression and sensitized MCF-7 MX-resistant cells to MX. Furthermore, in an in vivo approach, an intra-tumoral injection of miR-181a mimics inhibited ABCG2 expression, and enhanced the antitumor activity of MX. Other authors have also shown that ABCG2 is regulated by miR-328 ${ }^{[99,100]}$, miR-519 $\mathrm{c}^{[99]}$ and $\mathrm{miR}-487 \mathrm{a}^{[101]}$ in breast cancer and influences MX resistance. Li et al ${ }^{[99]}$ also showed that differences in expression of miR-519c and miR-328 are evident in stem celllike ABCG2+ cells and their ABCG2- counterparts. Thus, new insights about drug resistance can be discovered by investigating miRNAs regulation in stem cells. In fact, more recently, several studies have been published showing the effect of some miRNAs in cisplatin resistance by modulating the ABCG2 transporter in stem cells, more precisely, miR-199a/b in colorectal cancer stem cells through the Wnt/ 
$\beta$-catenin pathway (by directly targeting Gsk3 $\beta$ ), and the authors showed that miR-199a/b is over-expressed in ALDHA1+ (primary colorectal cancer stem cells) and contribute to cisplatin resistance. Thus, here the authors showed that the effect on ABCG2 is not direct ${ }^{[102]}$. Other authors reported that miR-132 modulates cisplatin resistance by targeting the SIRT1 gene in gastric cancer stem cells ${ }^{[103]}$. SIRT1 is a known upstream regulator of $\mathrm{ABCG} 2$ and the authors showed an inverse correlation between miR-132 and SIRT1 in gastric cancer tissues. Jia et al. ${ }^{[104]}$ showed that miR-3163 inhibits cisplatin resistance in retinoblastoma cancer stem cells. The authors validated ABCG2 as a target of miR-3163 and ABCG2 expression decreased significantly after ectopic overexpression of miR-3163. Finally, Guo et al ${ }^{[105]}$ reported a miR-495/UBE2C/ABCG2/ERCC1 axis as modulator of cisplatin resistance in non-small cell lung cancer cells. Once again, miR-495 is not a direct regulator of $\mathrm{ABCG} 2$ but instead regulates $\mathrm{UBE} 2 \mathrm{C}$ that has $\mathrm{ABCG} 2$ and $\mathrm{ERCC} 1$ as downstream targets.

\section{CONCLUSION}

The intricate circuitry of miRNAs, the post-transcriptional regulation they mediate and their possible role in CDR is still far from being clarified in all its aspects and consequences. Epigenetic regulation, particularly by miRNAs, besides DNA methylation or histone acetylation, apparently has an important role not only in carcinogenesis but also in cancer treatment. The more than 2000 different human microRNA species identified thus far are part of an intertwined network of concurrently regulated proteins that mediate cell survival upon a challenge by cancer drugs by controlling the levels of expression of genes coding for metabolizing enzymes and transporter proteins as outlined above, being thus connected with drug resistance. Besides miRNAs, also long non-coding RNAs may regulate mRNAs' levels of expression correlated with CDR. The fine tuning of the non-coding-RNAs system is also regulated by hypermethylation making the whole of the epigenetics a self-regulated system whose overall implications in CDR are yet to be fully uncovered but can hardly be considered as non-players in CDR and cancer therapy failure ${ }^{[1]}$.

\section{DECLARATIONS}

\section{Authors' contributions}

Wrote the paper: Gomes BC, Rueff J, Rodrigues AS

\section{Availability of data and materials}

Not applicable.

\section{Financial support and sponsorship}

The work received financial support from Centre of Toxicogenomics and Human health and IHMT. This work was supported by Fundação da Ciência e Tecnologia (FCT, Portugal) through grant (UID/ BIM/00009/2016).

\section{Conflicts of interest}

All authors declared that there are no conflicts of interest.

\section{Ethical approval and consent to participate}

Not applicable.

\section{Consent for publication}

Not applicable.

\section{Copyright}

(c) The Author(s) 2019. 


\section{REFERENCES}

1. Rueff J, Rodrigues AS. Cancer Drug Resistance: A Brief Overview from a Genetic Viewpoint. Methods Mol Biol 2016;1395:1-18.

2. Pathania S, Bhatia R, Baldi A, Singh R, Rawal RK. Drug metabolizing enzymes and their inhibitors' role in cancer resistance. Biomed Pharmacother. 2018;105:53-65.

3. Purnapatre K, Khattar SK, Saini KS. Cytochrome P450s in the development of target-based anticancer drugs. Cancer Lett 2008;259:1-15.

4. Robey RW, Pluchino KM, Hall MD, Fojo AT, Bates SE, et al. Revisiting the role of ABC transporters in multidrug-resistant cancer. Nat Rev Cancer 2018;18:452-64

5. Lee RC, Ambros V. An extensive class of small RNAs in Caenorhabditis elegans. Science 2001;294:862-4.

6. Lee RC, Feinbaum RL, Ambros V. The C. elegans heterochronic gene lin-4 encodes small RNAs with antisense complementarity to lin-14. Cell 1993;75:843-54.

7. Wightman B, Ha I, Ruvkun G. Posttranscriptional regulation of the heterochronic gene lin-14 by lin-4 mediates temporal pattern formation in C. elegans. Cell 1993;75:855-62.

8. Mattiske S, Suetani RJ, Neilsen PM, Callen DF. The oncogenic role of miR-155 in breast cancer. Cancer Epidemiol Biomarkers Prev 2012;21:1236-43.

9. Calin GA, Dumitru CD, Shimizu M, Bichi R, Zupo S, et al. Frequent deletions and down-regulation of micro- RNA genes miR15 and miR16 at 13q14 in chronic lymphocytic leukemia. Proc Natl Acad Sci USA 2002;99:15524-9.

10. Fojo T. Multiple paths to a drug resistance phenotype: Mutations, translocations, deletions and amplification of coding genes or promoter regions, epigenetic changes and microRNAs. Drug Resist Updat 2007;10:59-67.

11. Ikemura K, Iwamoto T, Okuda M. MicroRNAs as regulators of drug transporters, drug-metabolizing enzymes, and tight junctions: implication for intestinal barrier function. Pharmacol Ther 2014;143:217-24.

12. McKenna LB, Schug J, Vourekas A, McKenna JB, Bramswig NC, et al. MicroRNAs control intestinal epithelial differentiation, architecture, and barrier function. Gastroenterology 2010;139:1654-1664.e1.

13. Dalmasso G, Nguyen HTT, Yan Y, Laroui H, Charania MA, et al. MicroRNA-92b regulates expression of the oligopeptide transporter PepT1 in intestinal epithelial cells. Am J Physiol - Gastrointest Liver Physiol 2011;300:G52-9.

14. Pullen TJ, da Silva Xavier G, Kelsey G, Rutter GA. miR-29a and miR-29b Contribute to Pancreatic -Cell-Specific Silencing of Monocarboxylate Transporter 1 (Mct1). Mol Cell Biol 2011;31:3182-94.

15. Zhang JX, Xu Y, Gao Y, Chen C, Zheng ZS, et al. Decreased expression of miR-939 contributes to chemoresistance and metastasis of gastric cancer via dysregulation of SLC34A2 and Raf/MEK/ERK pathway. Mol Cancer 2017;16:18.

16. Hao G jun, Ding Y hui, Wen H, Li X feng, Zhang W, et al. Attenuation of deregulated miR-369-3p expression sensitizes non-small cell lung cancer cells to cisplatin via modulation of the nucleotide sugar transporter SLC35F5. Biochem Biophys Res Commun 2017;488:501-8.

17. Li P, Yang X, Cheng Y, Zhang X, Yang C, et al. MicroRNA-218 Increases the Sensitivity of Bladder Cancer to Cisplatin by Targeting Glut1. Cell Physiol Biochem 2017;41:921-32.

18. Annalora AJ, Marcus CB, Iversen PL. Alternative splicing in the cytochrome P450 superfamily expands protein diversity to augment gene function and redirect human drug metabolism. Drug Metab Dispos 2017;45:375-89.

19. Kim SM, Wang YQ, Nabavi N, Liu Y, Correia MA. Hepatic cytochromes P450: structural degrons and barcodes, posttranslational modifications and cellular adapters in the ERAD-endgame. Drug Metab Rev 2016;48:405-33.

20. Urquhart BL, Tirona RG, Kim RB. Nuclear receptors and the regulation of drug-metabolizing enzymes and drug transporters: implications for interindividual variability in response to drugs. J Clin Pharmacol 2007;47:566-78.

21. Dluzen DF, Lazarus P. MicroRNA regulation of the major drug-metabolizing enzymes and related transcription factors. Drug Metab Rev 2015;47:320-34.

22. Rodriguez-Antona C, Ingelman-Sundberg M. Cytochrome P450 pharmacogenetics and cancer. Oncogene 2006;251679-91.

23. Rendic S, Guengerich FP. Survey of human oxidoreductases and cytochrome P450 enzymes involved in the metabolism of xenobiotic and natural chemicals. Chem Res Toxicol 2015;28:38-42.

24. Bu Z Bin, Ye M, Cheng Y, Wu WZ. Four polymorphisms in the cytochrome P450 1A2 (CYP1A2) gene and lung cancer risk: A metaanalysis. Asian Pacific J Cancer Prev 2014;15:5673-9.

25. Elfaki I, Mir R, Almutairi FM, Abu Duhier FM. Cytochrome P450: Polymorphisms and roles in cancer, diabetes and atherosclerosis. Asian Pac J Cancer P 2018;19:2057-70.

26. Chen Y, Zeng L, Wang Y, Tolleson WH, Knox B, et al. The expression, induction and pharmacological activity of CYP1A2 are posttranscriptionally regulated by microRNA hsa-miR-132-5p. Biochem Pharmacol 2017;145:178-91.

27. Shimada T. Inhibition of carcinogen-activating cytochrome P450 enzymes by xenobiotic chemicals in relation to antimutagenicity and anticarcinogenicity. Toxicol Res 2017;33:79-96.

28. Blackburn HL, Ellsworth DL, Shriver CD, Ellsworth RE. Role of cytochrome P450 genes in breast cancer etiology and treatment: effects on estrogen biosynthesis, metabolism, and response to endocrine therapy. Cancer Cause Control 2015;26:319-32.

29. Economopoulos KP, Sergentanis TN. Three polymorphisms in cytochrome P450 1B1 (CYP1B1) gene and breast cancer risk: A metaanalysis. Breast Cancer Res Treat 2010;122:545-51.

30. Yin J, Sheng B, Qiu Y, Yang K, Xiao W, et al. Role of AhR in positive regulation of cell proliferation and survival. Cell Proliferat 2016;49:554-60.

31. Tsuchiya Y, Nakajima M, Takagi S, Taniya T, Yokoi T. MicroRNA regulates the expression of human cytochrome P450 1B1. Cancer Res 2006;66:9090-8. 
32. Crewe HK, Notley LM, Wunsch RM, Lennard MS, Gillam EM. Metabolism of tamoxifen by recombinant human cytochrome P450 enzymes: formation of the 4-hydroxy, 4'-hydroxy and N-desmethyl metabolites and isomerization of trans-4-hydroxytamoxifen. Drug Metab Dispos 2002;30:869-74.

33. Chuturgoon AA, Phulukdaree A, Moodley D. Fumonisin B1 modulates expression of human cytochrome P450 $1 \mathrm{~b} 1$ in human hepatoma (Hepg2) cells by repressing Mir-27b. Toxicol Lett 2014;227:50-5.

34. Chang I, Mitsui Y, Fukuhara S, Gill A, Wong DK, et al. Loss of miR-200c up-regulates CYP1B1 and confers docetaxel resistance in renal cell carcinoma. Oncotarget 2015;6:7774-87.

35. Mao M, Wu Z, Chen J. MicroRNA-187-5p suppresses cancer cell progression in non-small cell lung cancer (NSCLC) through downregulation of CYP1B1. Biochem Biophys Res Commun 2016;478:649-55.

36. Leung T, Rajendran R, Singh S, Garva R, Krstic-Demonacos M, et al. Cytochrome P450 2E1 (CYP2E1) regulates the response to oxidative stress and migration of breast cancer cells. Breast Cancer Res 2013;15:R107.

37. Daly AK. Genetic Polymorphisms Affecting Drug Metabolism. Recent Advances and Clinical Aspects. Adv Pharmacol 2012;63:137-67.

38. Mohri T, Nakajima M, Fukami T, Takamiya M, Aoki Y, et al. Human CYP2E1 is regulated by miR-378. Biochem Pharmacol 2010;79:1045-52.

39. Shukla U, Tumma N, Gratsch T, Dombkowski A, Novak RF. Insights into insulin-mediated regulation of CYP2E1: miR-132/-212 targeting of CYP2E1 and role of phosphatidylinositol 3-kinase, Akt (protein kinase B), mammalian target of rapamycin signaling in regulating miR-132/-212 and miR-122/-181a expression in pri. Drug Metab Dispos 2013;41:1769-77.

40. Miao L, Yao H, Li C, Pu M, Yao X, et al. A dual inhibition: MicroRNA-552 suppresses both transcription and translation of cytochrome P450 2E1. Biochim Biophys Acta - Gene Regul Mech 2016;1859:650-62.

41. Hu GX, Dai DP, Wang H, Huang XX, Zhou XY, et al. Systematic screening for CYP3A4 genetic polymorphisms in a Han Chinese population. Pharmacogenomics 2017;18:369-79.

42. Pan YZ, Gao W, Yu AM. MicroRNAs regulate CYP3A4 expression via direct and indirect targeting. Drug Metab Dispos 2009;37:2112-7.

43. Liu JE, Ren B, Tang L, Tang QJ, Liu XY, et al. The independent contribution of miRNAs to the missing heritability in CYP3A4/5 functionality and the metabolism of atorvastatin. Sci Rep 2016;6:26544.

44. Jones HM, Fang Z, Sun W, Clark LH, Stine JE, et al. Atorvastatin exhibits anti-tumorigenic and anti-metastatic effects in ovarian cancer in vitro. Am J Cancer Res 2017;7:2478-90.

45. Duffel MW, Marshall AD, McPhie P, Sharma V, Jakoby WB. Enzymatic aspects of the phenol (aryl) sulfotransferases. Drug Metab Rev 2001;33:369-95.

46. Mercer KE, Apostolov EO, da Costa GG, Yu X, Lang P, et al. Expression of sulfotransferase isoform 1A1 (SULT1A1) in breast cancer cells significantly increases 4-hydroxytamoxifen-induced apoptosis. Int J Mol Epidemiol Genet 2010;1:92-103.

47. Yu X, Dhakal IB, Beggs M, Edavana VK, Williams S, et al. Functional genetic variants in the 3'-untranslated region of sulfotransferase isoform 1A1 (SULT1A1) and their effect on enzymatic activity. Toxicol Sci 2010;118:391-403.

48. McLellan LI, Wolf CR. Glutathione and glutathione-dependent enzymes in cancer drug resistance. Drug Resist Updat 1999;2:153-64.

49. Sawers L, Ferguson MJ, Ihrig BR, Young HC, Chakravarty P, et al. Glutathione S-transferase P1 (GSTP1) directly influences platinum drug chemosensitivity in ovarian tumour cell lines. Br J Cancer 2014;111:1150-8.

50. Moriya Y, Nohata N, Kinoshita T, Mutallip M, Okamoto T, et al. Tumor suppressive microRNA-133a regulates novel molecular networks in lung squamous cell carcinoma. J Hum Genet 2012;57:38-45.

51. Dluzen DF, Sutliff AK, Chen G, Watson CJW, Ishmael FT, et al. Regulation of UGT2B Expression and Activity by miR-216b-5p in Liver Cancer Cell Lines. J Pharmacol Exp Ther 2016;359:182-93.

52. Margaillan G, Lévesque É, Guillemette C. Epigenetic regulation of steroid inactivating UDP-glucuronosyltransferases by microRNAs in prostate cancer. J Steroid Biochem Mol Biol 2016;155:85-93.

53. Papageorgiou I, Court MH. Identification and validation of microRNAs directly regulating the UDP-glucuronosyltransferase $1 \mathrm{~A}$ subfamily enzymes by a functional genomics approach. Biochem Pharmacol 2017;137:93-106.

54. Wijayakumara DD, Mackenzie PI, McKinnon RA, Hu DG, Meech R. Regulation of UDP-glucuronosyltransferases UGT2B4 and UGT2B7 by MicroRNAs in liver cancer cells. J Pharmacol Exp Ther 2017;361:386-97.

55. Stingl JC, Bartels H, Viviani R, Lehmann ML, Brockmöller J. Relevance of UDP-glucuronosyltransferase polymorphisms for drug dosing: A quantitative systematic review. Pharmacol Therapeut 2014;141:92-116.

56. Gottesman MM, Fojo T, Bates SE. Multidrug resistance in cancer: role of ATP-dependent transporters. Nat Rev Cancer 2002;2:48-58.

57. Armada A, Martins C, Spengler G, Molnar J, Amaral L, et al. Fluorimetric methods for analysis of permeability, drug transport kinetics, and inhibition of the ABCB1 membrane transporter. Methods Mol Biol 2016;1395:87-103.

58. Kathawala RJ, Gupta P, Ashby CR, Chen ZS. The modulation of ABC transporter-mediated multidrug resistance in cancer: A review of the past decade. Drug Resist Update 2015;18:1-17.

59. Gomes BC, Rueff J, Rodrigues AS. MicroRNAs and cancer drug resistance. Methods Mol Biol 2016;1395:137-62.

60. Haenisch S, Werk AN, Cascorbi I. MicroRNAs and their relevance to ABC transporters. Br J Clin Pharmacol 2014;77:587-96.

61. Dean M, Rzhetsky A, Allikmets R. The human ATP-binding cassette (ABC) transporter superfamily. Genome Res 2001;11:1156-66.

62. Vaidyanathan A, Sawers L, Gannon AL, Chakravarty P, Scott AL, et al. ABCB1 (MDR1) induction defines a common resistance mechanism in paclitaxel- and olaparib-resistant ovarian cancer cells. Br J Cancer 2016;115:431-41.

63. Jiang B, Yan LJ, Wu Q. ABCB1 (C1236T) Polymorphism Affects P-Glycoprotein-Mediated Transport of Methotrexate, Doxorubicin, Actinomycin D, and Etoposide. DNA Cell Biol 2019;38:485-90. 
64. Tecza K, Pamula-Pilat J, Lanuszewska J, Grzybowska E. Genetic polymorphisms and response to 5-fluorouracil, doxorubicin and cyclophosphamide chemotherapy in breast cancer patients. Oncotarget 2016;7:66790-808.

65. Hill CR, Jamieson D, Thomas HD, Brown CDA, Boddy AV, et al. Characterisation of the roles of ABCB1, ABCC1, ABCC2 and ABCG2 in the transport and pharmacokinetics of actinomycin D in vitro and in vivo. Biochem Pharmacol 2013;85:29-37.

66. Nakanishi T, Menju T, Nishikawa S, Takahashi K, Miyata R, et al. The synergistic role of ATP-dependent drug efflux pump and focal adhesion signaling pathways in vinorelbine resistance in lung cancer. Cancer Med 2018;7:408-19.

67. Gromicho M, Dinis J, Magalhães M, Fernandes AR, Tavares P, et al. Development of imatinib and dasatinib resistance: Dynamics of expression of drug transporters ABCB1, ABCC1, ABCG2, MVP, and SLC22A1. Leuk Lymphoma 2011;52:1980-90.

68. Wang J, Ye C, Liu J, Hu Y. UCA1 confers paclitaxel resistance to ovarian cancer through miR-129/ABCB1 axis. Biochem Biophys Res Commun 2018;501:1034-40.

69. Lu C, Shan Z, Li C, Yang L. MiR-129 regulates cisplatin-resistance in human gastric cancer cells by targeting P-gp. Biomed Pharmacother 2017;86:450-6.

70. Wu X, Zheng Y, Han B, Dong X. Long noncoding RNA BLACAT1 modulates ABCB1 to promote oxaliplatin resistance of gastric cancer via sponging miR-361. Biomed Pharmacother 2018;99:832-8.

71. Zhao Y, Qi X, Chen J, Wei W, Yu C, et al. The miR-491-3p/Sp3/ABCB1 axis attenuates multidrug resistance of hepatocellular carcinoma. Cancer Lett 2017;408:102-11.

72. Zhou H, Lin C, Zhang Y, Zhang X, Zhang C, et al. miR-506 enhances the sensitivity of human colorectal cancer cells to oxaliplatin by suppressing MDR1/P-gp expression. Cell Prolif 2017;50:e12341.

73. Ikemura K, Yamamoto M, Miyazaki S, Mizutani H, Iwamoto T, et al. MicroRNA-145 post-transcriptionally regulates the expression and function of P-glycoprotein in intestinal epithelial cells. Mol Pharmacol 2013;83:399-405.

74. Wang H, Zhan M, Xu SW, Chen W, Long MM, et al. MiR-218-5p restores sensitivity to gemcitabine through PRKCE/MDR1 axis in gallbladder cancer. Cell Death Dis 2017;8:e2770.

75. Wu D di, Li X song, Meng XN, Yan J, Zong Z hong. MicroRNA-873 mediates multidrug resistance in ovarian cancer cells by targeting ABCB1. Tumor Biol 2016;37:10499-506.

76. Chen J, Tian W, Cai H, He H, Deng Y. Down-regulation of microRNA-200c is associated with drug resistance in human breast cancer. Med Oncol 2012;29:2527-34.

77. Bao L, Hazari S, Mehra S, Kaushal D, Moroz K, et al. Increased expression of P-glycoprotein and doxorubicin chemoresistance of metastatic breast cancer is regulated by miR-298. Am J Pathol 2012;180:2490-503.

78. Kovalchuk O, Filkowski J, Meservy J, Ilnytskyy Y, Tryndyak VP, et al. Involvement of microRNA-451 in resistance of the MCF-7 breast cancer cells to chemotherapeutic drug doxorubicin. Mol Cancer Ther 2008;7:2152-9.

79. Zhu H, Wu H, Liu X, Evans BR, Medina DJ, et al. Role of MicroRNA miR-27a and miR-451 in the regulation of MDR1/P-glycoprotein expression in human cancer cells. Biochem Pharmacol 2008;76:582-8.

80. Yi D, Xu L, Wang R, Lu X, Sang J. miR-381 overcomes cisplatin resistance in breast cancer by targeting MDR1. Cell Biol Int 2019;43:12-21.

81. Xu Y, Ohms SJ, Li Z, Wang Q, Gong G, et al. Changes in the expression of miR-381 and miR-495 are inversely associated with the expression of the MDR1 gene and development of multi-drug resistance. Mukhopadhyay P, editor. PLoS One 2013;8:e82062.

82. Li Y, Zhao L, Li N, Miao Y, Zhou H, Jia L. MiR-9 regulates the multidrug resistance of chronic myelogenous leukemia by targeting ABCB1. Oncol Rep 2017;37:2193-200.

83. Zou Z, Zou R, Zong D, Shi Y, Chen J, et al. miR-495 sensitizes MDR cancer cells to the combination of doxorubicin and taxol by inhibiting MDR1 expression. J Cell Mol Med 2017;21:1929-43.

84. Cole SPC. Targeting Multidrug Resistance Protein 1 (MRP1, ABCC1 ): Past, Present, and Future. Annu Rev Pharmacol Toxicol 2014;54:95-117.

85. Chen ZS, Tiwari AK. Multidrug resistance proteins (MRPs/ABCCs) in cancer chemotherapy and genetic diseases. FEBS J 2011;278:3226-45.

86. Pogribny IP, Filkowski JN, Tryndyak VP, Golubov A, Shpyleva SI, et al. Alterations of microRNAs and their targets are associated with acquired resistance of MCF-7 breast cancer cells to cisplatin. Int J Cancer 2010;127:1785-94.

87. Liang Z, Wu H, Xia J, Li Y, Zhang Y, et al. Involvement of miR-326 in chemotherapy resistance of breast cancer through modulating expression of multidrug resistance-associated protein 1. Biochem Pharmacol 2010;79:817-24.

88. Pan YZ, Zhou A, Hu Z, Yu AM. Small nucleolar RNA-derived microRNA hsa-miR-1291 modulates cellular drug disposition through direct targeting of ABC transporter ABCC1. Drug Metab Dispos 2013;41:1744-51.

89. Zhan M, Zhao X, Wang H, Chen W, Xu S, et al. miR-145 sensitizes gallbladder cancer to cisplatin by regulating multidrug resistance associated protein 1. Tumor Biol 2016;37:10553-62.

90. Gao M, Miao L, Liu M, Li C, Yu C, et al. MiR-145 sensitizes breast cancer to doxorubicin by targeting multidrug resistance-associated protein-1. Oncotarget 2016;7:59714-26.

91. Pei K, Zhu JJ, Wang CE, Xie QL, Guo JY. MicroRNA-185-5p modulates chemosensitivity of human non-small cell lung cancer to cisplatin via targeting ABCC1. Eur Rev Med Pharmacol Sci 2016;20:4697-704.

92. Xu K, Liang X, Shen K, Cui D, Zheng Y, et al. miR-297 modulates multidrug resistance in human colorectal carcinoma by downregulating MRP-2. Biochem J 2012;446:291-300.

93. Wu K, Yang Y, Zhao J, Zhao S. BAG3-mediated miRNA let-7g and let-7i inhibit proliferation and enhance apoptosis of human esophageal carcinoma cells by targeting the drug transporter ABCC10. Cancer Lett 2016;371:125-33. 
94. Natarajan K, Xie Y, Baer MR, Ross DD. Role of breast cancer resistance protein (BCRP/ABCG2) in cancer drug resistance. Biochem Pharmacol 2012;83:1084-103.

95. Burger H, Foekens JA, Look MP, Meijer-van Gelder ME, Klijn JGM, et al. RNA expression of breast cancer resistance protein, lung resistance-related protein, multidrug resistance-associated proteins 1 and 2, and multidrug resistance gene 1 in breast cancer: Correlation with chemotherapeutic response. Clin Cancer Res 2003;9:827-36.

96. Selever J, Gu G, Lewis MT, Beyer A, Herynk MH, Covington KR, et al. Dicer-mediated upregulation of BCRP confers tamoxifen resistance in human breast cancer cells. Clin Cancer Res 2011;17:6510-21.

97. Shiozawa K, Oka M, Soda H, Yoshikawa M, Ikegami Y, et al. Reversal of breast cancer resistance protein (BCRP/ABCG2)-mediated drug resistance by novobiocin, a coumermycin antibiotic. Int J Cancer 2004;108:146-51.

98. Jiao X, Zhao L, Ma M, Bai X, He M, et al. MiR-181a enhances drug sensitivity in mitoxantone-resistant breast cancer cells by targeting breast cancer resistance protein (BCRP/ABCG2). Breast Cancer Res Treat 2013;139:717-30.

99. Li X, Pan YZ, Seigel GM, Hu ZH, Huang M, et al. Breast cancer resistance protein BCRP/ABCG2 regulatory microRNAs (hsa-miR-328, $-519 \mathrm{c}$ and -520h) and their differential expression in stem-like ABCG2+ cancer cells. Biochem Pharmacol 2011;81:783-92.

100. Pan YZ, Morris ME, Yu AM. MicroRNA-328 negatively regulates the expression of breast cancer resistance protein (BCRP/ABCG2) in human cancer cells. Mol Pharmacol 2009;75:1374-9.

101. Ma MT, He M, Wang Y, Jiao XY, Zhao L, et al. MiR-487a resensitizes mitoxantrone (MX)-resistant breast cancer cells (MCF-7/MX) to MX by targeting breast cancer resistance protein (BCRP/ABCG2). Cancer Lett 2013;339:107-15.

102. Chen B, Zhang D, Kuai J, Cheng M, Fang X, et al. Upregulation of mir-199a/b contributes to cisplatin resistance via Wnt/ $\beta$-cateninABCG2 signaling pathway in ALDHA1+ colorectal cancer stem cells. Tumor Biol 2017;39:1010428317715155.

103. Zhang L, Guo X, Zhang D, Fan Y, Qin L, et al. Upregulated miR-132 in Lgr5+ gastric cancer stem cell-like cells contributes to cisplatin-resistance via SIRT1/CREB/ABCG2 signaling pathway. Mol Carcinog 2017;56:2022-34.

104. Jia M, Wei Z, Liu P, Zhao X. Silencing of ABCG2 by microRNA-3163 inhibits multidrug resistance in retinoblastoma cancer stem cells. J Korean Med Sci 2016;31:836-42.

105. Guo J, Jin D, Wu Y, Yang L, Du J, et al. The miR 495-UBE2C-ABCG2/ERCC1 axis reverses cisplatin resistance by downregulating drug resistance genes in cisplatin-resistant non-small cell lung cancer cells. EBioMedicine 2018;35:204-21. 